\title{
PAPERS
}

\section{Damp housing and childhood asthma: validation of reporting of symptoms}

\author{
D P Strachan
}

\begin{abstract}
The relations among parental reports of respiratory symptoms, bronchospasm measured after exercise, and the presence of visible fungal mould in the home was assessed in a population sample of 7 year old children $(n=873)$. Wheeze in the past year was the symptom most closely associated with reported dampness and particularly with mould. The unadjusted odds ratio relating mould and wheeze was $3.70(95 \%$ confidence interval $2 \cdot 22$ to $6 \cdot 15)$, and after adjustment for housing tenure, number of people per room, number of smokers in the household, and gas cooking this remained highly significant (odds ratio $3.00(1.72$ to 5.25$)$ ). The reduction in forced expiratory volume in one second after six minutes of free running was used to validate reporting of wheeze. At all levels of measured bronchial lability wheeze was reported more commonly in the children from homes with mould. There was no significant difference in the degree of bronchospasm measured among children from homes with and without mould.

Awareness of dampness or mould in the home may be a determinant of parental reporting of symptoms and may account for much of the observed association between mould and respiratory symptoms.
\end{abstract}

\section{Introduction}

In industrialised countries people spend much of their life indoors, and interest in the public health effects of the indoor environment is growing. ${ }^{1}$ Children are particularly appropriate for investigation of the influence of environmental variables on respiratory disease because active smoking and occupational variables are excluded. Much attention has focused on the potential hazards from passive exposure to tobacco smoke ${ }^{2-4}$ and from nitrogen dioxide produced by gas cookers, unvented gas appliances, and paraffin heaters. ${ }^{3-7}$

A common cause of complaint to landlords and local authorities is condensation of moisture from humid indoor air on to cold surfaces, which forms unsightly damp patches and promotes the growth of fungal moulds. ${ }^{89}$ Surveys in Scotland and England have suggested that between one quarter and one third of homes may be affected to some degree. ${ }^{10}{ }^{11}$ Poor quality housing in general and dampness in particular are widely believed to be detrimental to respiratory health. ${ }^{12}$ Allergic reactions to house dust mites, which thrive in damp homes, ${ }^{1+15}$ or to the airborne spores of fungal moulds ${ }^{16}$ are plausible mechanisms for a causal link between damp conditions and symptoms related to asthma.

Few epidemiological studies have investigated this association, but two small studies in north west Edinburgh showed a positive relation between reported dampness and mould and respiratory symptoms in children. ${ }^{1317}$ Similar findings have been reported in adults. ${ }^{16}$ Dampness (assessed independently by environmental health officers) and high ambient humidity were found more commonly in the homes of children with respiratory symptoms, ${ }^{13} 19$ which indicated that reporting of housing conditions was not substantially biased by the presence of disease in the child. On the other hand, when consultations with general practitioners for respiratory complaints were used to validate reporting of symptoms there was no association with reported dampness or mould. ${ }^{17}$ This raised the possibility that symptoms were reported differently according to parents' perception of their home environment.

My study was designed to investigate damp, mouldy housing as a determinant of childhood asthma in a representative sample of the general population and to evaluate the role of differential reporting of symptoms in any association. In view of the limitations of general practice records for this purpose the symptoms were validated by physiological tests to detect abnormal reactivity of the airways. ${ }^{20}$

\section{Subjects and methods}

A random sample of one in three primary schools within the Edinburgh city boundary was obtained. The parents of all children in their third primary school year (age 61/2-71/2 years) were contacted by post in November 1986. A questionnaire asked about respiratory symptoms experienced by the child in the past year, including wheeze (defined as breathing that makes a high pitched whistling sound), a tendency for colds to go to the chest, sore throat, pain or discharge in the ear, and hay fever or frequent sneezing attacks. Parents were also asked how many nights the child had been kept awake by coughing during the previous month and how many days in the month the child had been troubled by daytime cough or by a blocked or running nose. Information was sought about conditions in the home, particularly the number of cigarette smokers in the household, the fuels used for heating and cooking, the formation of condensation or damp patches on walls, and the presence of mould or fungus.

Consent was requested for medical tests on the child at school, and the study received ethical approval from Lothian Health Board and Lothian Regional Council Education Department. Ventilatory function was measured with a pneumotachograph (Compact; Vitalograph, Buckingham), and spirometry was performed with the child standing and without nose clips; I supervised all measurements using the protocol of the American Thoracic Society. ${ }^{21}$ Measurements were taken before and five and 10 minutes after six minutes of free running in a corridor or classroom; the best of three recordings on each occasion was used. An index of bronchial lability induced by exercise was calculated as the minimum of the two measurements of forced expiratory volume in one second taken after exercise divided by the forced expiratory volume in one 
second obtained before exercise. Tests were performed at least six hours after a dose of inhaled bronchodilator. Eleven children were taking inhaled steroids or oral drugs for asthma; their results were analysed separately.

Routine statistical analysis was performed with the Statistical Analysis System. ${ }^{22}$ To explore in more detail the relations between symptoms and housing conditions and between mould, wheeze, and bronchial lability multiple logistic regression models were analysed with the generalised linear interactive modelling system. ${ }^{23}$

\section{Results}

The parents of 1095 children received a questionnaire, and usable replies were obtained for 1012 . Information on respiratory symptoms and housing conditions was available for 926-1004, depending on the detail required. Parental consent for clinical testing was obtained for 941 children. Twenty of these were included in pilot studies, and a further 20 moved to a different school before testing. Of the remaining 901 children, 892 were examined and 881 performed a satisfactory exercise test.

Complete information on dampness, mould, wheeze, and bronchial lability was available for 873 children $(80 \%$ of the original sample, $97 \%$ of those eligible for testing). The prevalences of wheeze in the past year $(12.7 \% ; 111 / 873)$ and exposure to mould in the home $(9 \cdot 3 \% ; 81 / 873)$ were somewhat higher in this group than among those with incomplete information $(10.0 \%(13 / 130)$ and $6.3 \%(8 / 127)$, respectively).

Table I relates respiratory symptoms to various aspects of the home environment. The prevalences of wheeze and chesty colds were higher by a factor of between two and three among the children from homes reported to be affected by damp patches on walls or by mould; the higher prevalences among children sleeping in damp or mouldy bedrooms might be interpreted as evidence of a dose-response relation. Cough at night and during the daytime was significantly more common among children sleeping in damp bedrooms ( $p<0.001$ and $p<0.05$, respectively), and a smaller excess was observed in children sleeping in bedrooms affected by mould. Mould in the child's bedroom was significantly related to frequent trouble with a blocked or running nose $(p<0.05)$. The prevalences of cough at night and chesty colds were associated with crowding and the presence of smokers in the household. Domestic fuels were not important influences on the prevalence of respiratory symptoms. Paradoxically, chesty colds were considerably less common in children in households using gas for cooking but more prevalent in the small number of children exposed to unvented gas heating appliances. These relations in part reflected differences in the use of fuels by owner occupiers and tenants of rented housing. The pattern of association between dampness and hay fever was inconsistent; the difference in prevalence between all damp homes considered together and homes not affected was negligible $\left(\chi^{2}=0 \cdot 54, \mathrm{df}=1\right)$.

The association between damp, mouldy housing and wheeze was remarkable in view of the lack of a relation of wheeze to other environmental factors in the home. Compared with rented homes, owner occupied homes were less likely to be affected by dampness $(83 \%$ $(58 / 700) v 29.7 \%(89 / 300))$ or mould $(4.9 \%(34 / 700) v$ $18 \cdot 3 \%(55 / 300))$; this accounted for the difference in the prevalence of wheeze by housing tenure. In homes not affected by damp or mould the prevalence of wheeze was similar in the rented sector $(11 \cdot 1 \% ; 23 / 207)$ and in owner occupied homes $(10.6 \% ; 67 / 631)$. By contrast, chesty colds, cough at night, cough during the day, and running nose were influenced by the number of people per room and the number of smokers in the household, factors that were strongly related to tenure and were therefore potential confounders for the relation to dampness or mould.

Possible confounding effects were investigated by multiple logistic regression models with wheeze in the past year as the outcome variable. The unadjusted odds ratio for mould anywhere in the home was 3.70 ( $95 \%$ confidence interval $2 \cdot 22$ to $6 \cdot 15 ; \chi^{2}=27 \cdot 7, \mathrm{df}=1$ ). In a model that included housing tenure, number of smokers in the household, number of people per room, and gas cooking the odds ratio for mould was 3.00 $\left(1 \cdot 72\right.$ to $\left.5 \cdot 25 ; \chi^{2}=15 \cdot 2, \mathrm{df}=1\right)$. The effect of mould was independent of housing tenure $\left(\chi^{2}\right.$ for interaction term $=0 \cdot 41, \mathrm{df}=1)$. There was a close correlation

TABLE I-Prevalence (\%) of respiratory symptoms related to home environment. Numbers of children are given in parentheses

\begin{tabular}{|c|c|c|c|c|c|c|c|c|}
\hline & $\begin{array}{l}\text { Wheeze } \\
\text { (during } \\
\text { past year) }\end{array}$ & $\begin{array}{l}\text { Chesty colds } \\
\text { (during } \\
\text { past year) }\end{array}$ & $\begin{array}{l}\text { Cough at night } \\
(\geqslant 3 \text { nights in } \\
\text { past month })\end{array}$ & $\begin{array}{l}\text { Cough during day } \\
(\geqslant 3 \text { days in } \\
\text { past month })\end{array}$ & $\begin{array}{l}\text { Running nose } \\
\text { ( } \geqslant 7 \text { days in } \\
\text { past month) }\end{array}$ & $\begin{array}{l}\text { Hay fever } \\
\text { (during } \\
\text { past year) }\end{array}$ & $\begin{array}{l}\text { Ear trouble } \\
\text { (during } \\
\text { past year) }\end{array}$ & $\begin{array}{l}\text { Sore throat } \\
\text { (during } \\
\text { past year) }\end{array}$ \\
\hline \multicolumn{9}{|l|}{ Tenure: } \\
\hline $\begin{array}{l}\text { Owners } \\
\text { Renting }\end{array}$ & $\begin{array}{l}10 \cdot 7(75 / 702) \\
16 \cdot 3^{\star}(49 / 301)\end{array}$ & $\begin{array}{l}13 \cdot 5(93 / 690) \\
27 \cdot 4^{\star \star \star}(80 / 292)\end{array}$ & $\begin{array}{c}7 \cdot 8(54 / 692) \\
22 \cdot 5 \star \star \star(66 / 293)\end{array}$ & $\begin{array}{l}13 \cdot 2(91 / 689) \\
22 \cdot 0^{\star \star \star}(63 / 286)\end{array}$ & $\begin{array}{l}12 \cdot 5(85 / 682) \\
19 \cdot 0^{\star}(54 / 284)\end{array}$ & $\begin{array}{r}10 \cdot 8(74 / 684) \\
8 \cdot 5(24 / 281)\end{array}$ & $\begin{array}{l}24 \cdot 1(165 / 685) \\
24 \cdot 3(70 / 288)\end{array}$ & $\begin{array}{l}50 \cdot 4(348 / 691) \\
56 \cdot 3(166 / 295)\end{array}$ \\
\hline \multicolumn{9}{|l|}{ People per room: } \\
\hline$<1.0$ & $11 \cdot 5(39 / 338)$ & $15 \cdot 6(52 / 334)$ & $8 \cdot 0(27 / 336)$ & $13 \cdot 4(45 / 335)$ & $12 \cdot 4(41 / 331)$ & $9 \cdot 6(32 / 332)$ & $26 \cdot 3(88 / 334)$ & $51 \cdot 2(172 / 336)$ \\
\hline $1-1.5$ & $13 \cdot 3(66 / 496)$ & $17 \cdot 2(84 / 487)$ & $13 \cdot 0 \star(63 / 486)$ & $17 \cdot 1(83 / 484)$ & $16 \cdot 1(77 / 477)$ & $10 \cdot 5(50 / 478)$ & $22 \cdot 1(106 / 480)$ & $51 \cdot 9(252 / 486)$ \\
\hline$>1.5$ & $11 \cdot 1(14 / 126)$ & $25 \cdot 0^{\star}(31 / 124)$ & $18 \cdot 7^{\star \star}(23 / 123)$ & $15 \cdot 4(18 / 117)$ & $13 \cdot 6(16 / 118)$ & $10 \cdot 8(13 / 120)$ & $23 \cdot 0(28 / 122)$ & $54 \cdot 4(68 / 125)$ \\
\hline \multicolumn{9}{|l|}{ Smokers in household: } \\
\hline 0 & $12 \cdot 1(64 / 530)$ & $14 \cdot 8(77 / 519)$ & $9 \cdot 0(47 / 523)$ & $13.9(72 / 519)$ & $10 \cdot 9(56 / 513)$ & $10 \cdot 2(53 / 518)$ & $23 \cdot 5(122 / 519)$ & $51 \cdot 1(268 / 524)$ \\
\hline 1 & $12 \cdot 1(37 / 307)$ & $18.4(55 / 299)$ & $14 \cdot 0^{\star}(42 / 301)$ & $16 \cdot 5(49 / 297)$ & $17 \cdot 2^{\star}(51 / 297)$ & $10 \cdot 3(30 / 290)$ & $25 \cdot 3(75 / 296)$ & $52.5(158 / 301)$ \\
\hline$\geqslant 2$ & $13 \cdot 4(22 / 164)$ & $25 \cdot 3^{\star \star}(41 / 162)$ & $19 \cdot 5 \star \star \star(31 / 159)$ & $20 \cdot 4(32 / 157)$ & $20 \cdot 1^{\star \star}(31 / 154)$ & $9 \cdot 7(15 / 155)$ & $24 \cdot 4(38 / 156)$ & $55 \cdot 3(88 / 159)$ \\
\hline \multicolumn{9}{|l|}{ Gas cooker: } \\
\hline No & $13 \cdot 0(55 / 422)$ & $21 \cdot 0(87 / 414)$ & $13 \cdot 5(56 / 415)$ & $15 \cdot 3(63 / 411)$ & $14 \cdot 7(59 / 402)$ & $10 \cdot 6(43 / 405)$ & $21.9(89 / 407)$ & $53 \cdot 1(220 / 414)$ \\
\hline Yes & $11 \cdot 7(68 / 579)$ & $15 \cdot 2 \star(86 / 566)$ & $11 \cdot 2(64 / 569)$ & $16 \cdot 0(90 / 563)$ & $14 \cdot 2(80 / 564)$ & $9 \cdot 7(54 / 558)$ & $25.9(146 / 564)$ & $51 \cdot 4(293 / 570)$ \\
\hline \multicolumn{9}{|l|}{ Bottled gas stove: } \\
\hline No & $12 \cdot 4(114 / 920)$ & $16 \cdot 8(151 / 901)$ & $11 \cdot 9(108 / 905)$ & $15 \cdot 8(141 / 895)$ & $14 \cdot 5(129 / 887)$ & $10 \cdot 2(91 / 889)$ & $24 \cdot 0(214 / 892)$ & $51 \cdot 7(467 / 904)$ \\
\hline Yes & $12 \cdot 8(10 / 78)$ & $27 \cdot 6^{\star}(21 / 76)$ & $13 \cdot 2(10 / 76)$ & $14 \cdot 3(11 / 77)$ & $10 \cdot 8(8 / 74)$ & $9 \cdot 7(7 / 72)$ & $23 \cdot 7(18 / 76)$ & $55 \cdot 8(43 / 77)$ \\
\hline \multicolumn{9}{|l|}{ Paraffin heater: } \\
\hline No & $12 \cdot 4(121 / 974)$ & $17 \cdot 6(168 / 953)$ & $11 \cdot 8(113 / 958)$ & $15 \cdot 6(148 / 949)$ & $14 \cdot 0(131 / 939)$ & $10.4(97 / 937)$ & $24 \cdot 1(228 / 945)$ & $52 \cdot 0(498 / 958)$ \\
\hline Yes & $12 \cdot 5(3 / 24)$ & $16 \cdot 7(4 / 24)$ & $21 \cdot 7(5 / 23)$ & $17 \cdot 4(4 / 23)$ & $27 \cdot 3(6 / 22)$ & $4 \cdot 2(1 / 24)$ & $17 \cdot 4(4 / 23)$ & $52 \cdot 2(12 / 23)$ \\
\hline \multicolumn{9}{|l|}{ Coal fire: } \\
\hline No & $12 \cdot 5(117 / 937)$ & $17 \cdot 5(161 / 918)$ & $11 \cdot 7(108 / 921)$ & $15 \cdot 2(139 / 912)$ & $13 \cdot 7(124 / 904)$ & $10 \cdot 4(94 / 903)$ & $23.7(215 / 909)$ & $51 \cdot 6(475 / 920)$ \\
\hline Yes & $11 \cdot 5(7 / 61)$ & $18 \cdot 7(11 / 59)$ & $21 \cdot 7(5 / 23)$ & $17 \cdot 4(4 / 23)$ & $22 \cdot 8(13 / 57)$ & $6.9(4 / 58)$ & $28 \cdot 8(17 / 59)$ & $57 \cdot 4(35 / 61)$ \\
\hline \multicolumn{9}{|l|}{ Damp: } \\
\hline None & $10 \cdot 6(90 / 853)$ & $15 \cdot 3(128 / 839)$ & $10 \cdot 7(90 / 841)$ & $14 \cdot 7(123 / 834)$ & $13 \cdot 8(114 / 824)$ & $9 \cdot 7(80 / 824)$ & $23 \cdot 8(197 / 829)$ & $50 \cdot 8(427 / 840)$ \\
\hline Other rooms $\dagger$ & $20 \cdot 9 \star \star(18 / 86)$ & $25 \cdot 6^{\star}(21 / 82)$ & $11 \cdot 1(9 / 81)$ & $18 \cdot 5(15 / 81)$ & $17 \cdot 3(14 / 81)$ & $14 \cdot 3^{\star \star}(12 / 84)$ & $32 \cdot 1(27 / 84)$ & $60 \cdot 0(51 / 85)$ \\
\hline Child's bedroom & $24 \cdot 6^{\star \star}(15 / 61)$ & $37 \cdot 3^{\star \star \star}(22 / 59)$ & $31 \cdot 1^{\star \star \star}(19 / 61)$ & $25 \cdot 9 \star(15 / 58)$ & $17 \cdot 2(10 / 58)$ & $8 \cdot 9(5 / 56)$ & $18 \cdot 3(11 / 60)$ & $56 \cdot 7(34 / 60)$ \\
\hline \multicolumn{9}{|l|}{ Mould: } \\
\hline None & $10 \cdot 5(96 / 911)$ & $15 \cdot 6(140 / 895)$ & $11 \cdot 7(105 / 896)$ & $15 \cdot 3(136 / 889)$ & $13 \cdot 3(117 / 878)$ & $9 \cdot 8(86 / 882)$ & $23 \cdot 2(206 / 888)$ & $52 \cdot 1(468 / 899)$ \\
\hline Other rooms $\dagger$ & $23 \cdot 4^{\star}(11 / 47)$ & $32 \cdot 6^{\star \star}(15 / 46)$ & $12 \cdot 8(6 / 47)$ & $17 \cdot 0(8 / 47)$ & $23.4(11 / 47)$ & $20.0(9 / 45)$ & $35 \cdot 6(16 / 45)$ & $46 \cdot 7(21 / 45)$ \\
\hline Child's bedroom & $38 \cdot 1^{\star \star \star}(16 / 42)$ & $43 \cdot 6^{\star \star \star}(17 / 39)$ & $21 \cdot 4(9 / 42)$ & $26 \cdot 3(10 / 38)$ & $26 \cdot 3^{\star}(10 / 38)$ & $7 \cdot 9(3 / 38)$ & $30 \cdot 8(12 / 39)$ & $55 \cdot 0(22 / 40)$ \\
\hline
\end{tabular}

${ }^{\star} \mathrm{p}<0.05,{ }^{\star \star} \mathrm{p}<0.01,{ }^{\star \star \star} \mathrm{p}<0.001$ compared with prevalence in uppermost category. 
between damp walls and mould: $48 \%$ (71/147) of the homes affected by dampness were reported to be mouldy, and $80 \%(71 / 89)$ of the mouldy homes were reported to be damp. Mould seemed to have a greater effect on wheeze than did damp. In a model that included damp walls anywhere in the house the effect of mould remained significant $\left(\chi^{2}=7 \cdot 52, \mathrm{df}=1\right)$, whereas the effect of dampness independent of mould was negligible $\left(\chi^{2}=0.60, \mathrm{df}=1\right)$.

The relations between housing conditions and chest colds, cough at night, cough during the day, and nasal discharge were investigated in similar multiple logistic regression models with each respiratory symptom in turn as the outcome variable. The association between mould and chest colds was independent of housing tenure, number of people per room, number of smokers, and gas cooking (odds ratio 2.08 (1.22-3.51); $\chi^{2}=7 \cdot 26, \mathrm{df}=1$ ). Inclusion of wheeze during the past year as a further explanatory variable reduced this effect so that it was no longer significant, although it remained in the same direction (odds ratio $1.43(0.77$ to $2 \cdot 70)$ ). At least part of the association between chesty colds and mould thus seemed to be a consequence of a recent tendency to wheeze.

The weaker associations of cough at night and during the day with mould in the home were entirely explained by their common association with rented housing. After adjustment for tenure the odds ratios for cough at night and cough during the day associated with mould were 0.92 and 0.95 , respectively, and the effect of mould on nasal discharge remained in the expected direction but was non-significant (odds ratio $1.61(0.89$ to 2.90$\left.) ; \chi^{2}=2 \cdot 42, \mathrm{df}=1\right)$. Further adjustment for the effects of number of people per room, number of smokers, and gas cooking made little difference to these results.

Objective evidence of airways reactivity was collected to investigate the possible contribution of bias in reporting to the observed association between wheeze and mould in data from this and a previous questionnaire. ${ }^{17}$ As expected, wheeze during the past year was more prevalent among the children who had bronchospasm after exercise. If no reporting bias had existed this relation would have been independent of housing conditions. In fact, for any given degree of bronchial lability a parental report of wheezing was more commonly obtained for children from homes with mould (table II). In a logistic regression model with wheeze during the past year as the outcome bronchial lability was included as a continuous explanatory variable. Its relation to wheeze was roughly linear $\left(\chi^{2}\right.$ for quadratic term $\left.=1.05, \mathrm{df}=1\right)$ and was modelled as such. The effect of mould in the home was independent of lability (odds ratio $3 \cdot 50$ $\left.(1 \cdot 95-6 \cdot 47) ; \quad \chi^{2}=16 \cdot 1, \mathrm{df}=1\right)$ and constant across the range of lability observed ( $\chi^{2}$ for interaction term $=0 \cdot 10, \mathrm{df}=1)$. This odds ratio of 3.5 was comparable with the odds ratio of 3.7 obtained in the earlier model, which excluded lability; this implies that

TABLE II - Prevalence (\%) of wheeze in past year related to mould in home and bronchial lability induced by exercise. Numbers of children are given in parentheses

\begin{tabular}{lccc}
\hline Lability index & No mould & Mould in any room & \multicolumn{1}{c}{ Total } \\
\hline$<0 \cdot 8$ & $48 \cdot 6(17 / 35)$ & $60 \cdot 0(3 / 5)$ & $50 \cdot 0(20 / 40)$ \\
$0 \cdot 8-0 \cdot 89$ & $11 \cdot 1(7 / 63)$ & $44 \cdot 4(4 / 9)$ & $15 \cdot 3(11 / 72)$ \\
$0.9-0.99$ & $8 \cdot 9(34 / 383)$ & $33 \cdot 3(10 / 30)$ & $10 \cdot 7(44 / 413)$ \\
$\geqslant 1.0$ & $6 \cdot 6(20 / 303)$ & $14 \cdot 7(5 / 34)$ & $7 \cdot 4(25 / 337)$ \\
\hline Total & $10 \cdot 9(86 / 792) \dagger$ & $30 \cdot 9(25 / 81) \ddagger$ & $12 \cdot 7(111 / 873) \dagger \ddagger$
\end{tabular}

^Forced expiratory volume in one second after exercise divided by tha before exercise.

tIncludes eight children tested while receiving treatment, all of whom wheezed.

IIncludes three children tested while receiving treatment, all of whom wheezed. the relation between mould and wheeze was largely unrelated to measurements of airways reactivity.

The higher prevalence of reported wheeze among children from homes with mould for any degree of airways reactivity suggested that reporting bias explained a substantial part of the association of wheeze with damp or mouldy housing. Bronchospasm after exercise (lability index $<0 \cdot 8$ ) was, however, more common among the children from homes with mould. On the generous (but not unreasonable) assumption that all the children receiving drug treatment for asthma who were tested had reactive airways, the prevalence of abnormality was $9.9 \%$ (8/81) among children from homes with mould compared with $5 \cdot 4 \%(43 / 792)$ among the remainder (table II). This difference was in the expected direction, although it did not reach significance $\left(\chi^{2}=1 \cdot 90, \mathrm{df}=1\right)$. A non-parametric comparison of the entire distribution of lability in children from homes with and without mould was made using normal scores from the RANK procedure in $\mathrm{SAS}^{22}$ to correct for the pronounced skewness. The difference between the two groups was negligible (Student's $t=0 \cdot 4, \mathrm{df}=860$ ).

\section{Discussion}

This study confirms the finding of previous surveys in one part of Edinburgh and suggests that an association between damp or mouldy housing and respiratory symptoms is not confined to specific council estates or to rented as opposed to owner occupied housing. ${ }^{1317}$ The association between mould and wheeze meets many of the criteria for an epidemiological association to be considered causal: it is strong, relatively specific when compared with other symptoms, consistent with previous studies, and free of substantial confounding by other factors studied. ${ }^{24}$ Biologically plausible causal mechanisms can be proposed, and, assuming that duration of exposure is greatest when the child's bedroom is affected by mould or damp, there is a suggestion of a dose-response relation.

The association of wheeze with damp or mouldy housing was of particular interest not only because confounding by other features of the home environment was unlikely but also because a primary association with wheeze might account for the effect of damp, mouldy housing on other respiratory symptoms related to asthma. Furthermore, wheeze was the symptom for which a causal link with damp housing conditions was most plausible biologically.

The prevalence ratio for wheeze in the past year when homes with and without mould were compared is remarkable in view of the lack of correlation of most social or environmental variables with childhood asthma. ${ }^{25} 26$ The study sample was drawn from the general population and permitted an estimate of the importance to public health of this association. If no child in the population of 1000 had been exposed to mould in the home 105 cases of wheeze during the past year would have been expected, based on 96 cases in 911 children (table I). As 123 cases were seen mould in the home accounted for $14 \%(18 / 123)$ of all cases of wheeze. This fraction of the population attributable risk varied with the prevalence of exposure, being $6 \%$ $(4 \cdot 5 / 75)$ for children from owner occupied homes but $26 \%(12 \cdot 5 / 49)$ for children from rented homes. These proportions are certainly much greater than any corresponding hazards from cooking or heating fuels.

In a study of adults $43 \%$ of those living in areas of poor quality housing associated respiratory symptoms with their housing whereas in areas of good housing only $10 \%$ did so. ${ }^{12}$ Differences such as this may reflect a causal relation, but they raise the possibility that reports of health state and particularly of respiratory symptoms may be influenced by perceptions of the 
home environment. The present study showed that at any given level of airways reactivity induced by exercise the prevalence of wheeze reported by parents of children from homes with mould was substantially higher than the prevalence reported for children from unaffected homes. Interpretation of these results depends on the validity of the exercise challenge as an objective indicator of respiratory disease.

Exercise was chosen because it is a common physiological challenge and therefore positive findings can be considered to have intrinsic validity. Pharmacological challenge tests may be more sensitive to minor degrees of airways reactivity, but they can induce bronchospasm in many non-wheezy children, which makes the interpretation of positive results less certain. ${ }^{27}$ Although wheeze and bronchial lability were clearly related, in two thirds of the wheezy children the forced expiratory volume in one second after exercise was within $10 \%$ of the value determined before exercise. Any assessment of change in a spirometric index is sensitive to errors of measurement, particularly in this young age group. Repeating the measurements in the same population of children suggested that forced expiratory volume in one second was the most reproducible spirometric index, but its coefficient of variation within subjects on any given occasion was $8.5 \%$; hence the lability index was subject to substantial random errors of measurement and individual subjects were misclassified.

Though lack of sensitivity and random errors in the test procedure may have reduced the power of the study to detect a true relation between reported mould and bronchial lability, the negative findings do not exclude an association. These limitations cannot, however, explain the different relations between wheeze and lability in the children from homes with and without mould. This difference could be explained if exposure to mould commonly resulted in a syndrome (or a subtype of asthma) that caused wheeze but was not associated with airways reactivity to exercise. By its very nature this is a difficult proposition to test objectively, but it is unlikely for two reasons. Firstly, epidemiological and clinical evidence supports the concept of childhood asthma as a single disease, the cardinal symptom of which is wheeze. ${ }^{27} 28$ Secondly, the most plausible causal mechanism for any association between mould and wheeze is allergy to airborne spores, but atopic skin reactions to common antigens are associated with more frequent wheeze,,$^{29}$ and children who wheeze more frequently are more likely to show airways reactivity. ${ }^{27}$

An alternative argument might be that bronchospasm induced by exercise reflects an underlying susceptibility to asthmatic attacks rather than the activity of the disease itself. In this case the prevalence of symptoms might depend on both host factors (non-specific bronchial hyperreactivity) and the "dose" of trigger factors in the environment (including mould spores). The results presented in table II could be interpreted as showing this, given that lability induced by exercise was an imprecise measure of underlying airways reactivity and that mould may not be a trigger for all susceptible children. Such a distinction between host and environmental factors is, however, called into question by observations that when patients with sensitivity to house dust mite move to an environment free of allergens the response of their bronchi to inhaled histamine is reduced. ${ }^{30}$ This suggests that non-specific bronchial hyperreactivity can result from long term exposure to allergen and is a manifestation of asthma rather than a cofactor in its aetiology.

The most straightforward explanation of the discrepancy between the questionnaire and clinical data is that awareness of dampness or mould in the home is a determinant of parental reporting of symptoms; this would account for much of the observed association between mould and respiratory symptoms. The use of the term reporting bias should not be misunderstood. It does not mean that the accuracy of reporting by occupants of homes with mould is necessarily poorer; recall of symptoms for children in homes not affected by mould may be less complete. This reporting bias, however, implies that further studies of this relation are unlikely to be valid if they rely solely on information from questionnaires. An alternative source of reporting bias, which has not been considered here, is the effect of the child's symptoms on parental awareness of adverse conditions in the home. Ambient humidity and airborne fungal spores are being measured in subsamples of the study population to address this issue.

I thank the Asthma Research Council for financial support; the schoolteachers, whose willing cooperation was invaluable at all stages of the survey; Mrs P Ross for help with the medical examinations; and $\operatorname{Dr} M$ Fulton for advice and encouragement throughout the study

1 Mant DC, Gray JAM. Building regulation and health. Watford: Building Research Establishment, 1986

2 Holt PG, Turner KJ. Respiratory symptoms in the children of smokers: an overview. Eur f Respir Dis [Suppl] 1984;133:109-17.

3 Ware JH, Dockery DW, Spiro A III, Speizer FE, Ferris BG. Passive smoking, gas cooking and respiratory health of children living in six cities. Am Rev Respir Dis 1984;129:366-73.

4 Ogston SA, Florey CV, Walker CHM. The Tayside infant morbidity and mortality study: effect on health of using gas for cooking. Br Med $\mathcal{J}$ 1985;290:957-60

5 Melia RJW, Florey CV, Chinn S. The relation between respiratory illness in primary schoolchildren and the use of gas for cooking. I. Results from national survey. Int $\mathcal{f}$ Epidemiol 1979;8:333-8.

6 Goldstein BD, Melia RJW, Chinn S, Florey CV, Clark D, John HH. The relation between respiratory illness in primary schoolchildren and the use of gas for cooking. II. Factors affecting nitrogen dioxide levels in the home. Int $\mathcal{F}$ Epidemiol 1979;8:339-45.

7 Leaderer BP. Air pollutant emissions from kerosene space heaters. Science 1982:218:1113-4.

8 Sanders $\mathrm{CH}$, Cornish JP. Dampness: one week's complaints in five local authorities in England and Wales. London: HMSO, 1982.

9 Block SS. Humidity requirements for mould growth. Applied Microbiology 1953;1:287-93.

10 Scottish Development Department Building Directorate. Condensation in housing: a report on local authority returns, survey results and remedial measures. Edinburgh: Scottish Office, 198

11 Building Research Establishment. The English house condition survey. London HMSO, 1985.

12 McCarthy P, Byrne D, Harrison S, Keithly J. Respiratory conditions: effect of housing and other factors. $\mathcal{F}$ Epidemiol Community Health 1985;39:15-9.

13 Martin CJ, Platt SD, Hunt SM. Housing conditions and ill-health. Br Med 1987;294:1125-7.

14 Blythe ME. Some aspects of the ecological study of the house dust mites. $\mathrm{Br} f$ Dis Chest 1976;70:3-31

15 Burr ML, Dean BV, Merrell TG, et al. Effects of anti-mite measures on children with mite-sensitive asthma: a controlled trial. Thorax 1980;35: 506-12.

16 Burr ML, Mullins J, Merret TG, Stott NCH. Asthma and indoor mould exposure. Thorax 1985;40:688.

17 Strachan DP, Elton RA. Relationship between respiratory morbidity in children and the home environment. Family Practice 1986;3:137-42.

18 Burr ML, St Leger AS, Yarnell JWG. Wheezing, dampness and coal fires Community Med 1981;3:205-9.

19 Melia RJW, Florey CV, Morris RW, et al. Childhood respiratory illness and the home environment. II. Association between respiratory illness and nitrogen dioxide, temperature and relative humidity. Int $\mathcal{f}$ Epidemio 1982;11:164-9.

20 Silverman $M$, Anderson SD. Standardization of exercise tests in asthmatic children. Arch Dis Child 1972;47:882-9.

21 American Thoracic Society. Snowbird workshop on standardization of spirometry. Am Rev Respir Dis 1979;119:831-8.

22 SAS Institute. SAS user's guide: basics and statistics, version 5 edition. Cary, North Carolina: SAS Institute, 1985.

23 Baker RJ, Nelder JA. The GLIM system manual, release 3. Oxford: Numerical A Rorito

24 Bradford-Hill A. The environment and disease: association or causation? $\mathcal{f} R$ Soc Med 1965:58:295-300

25 Anderson HR, Bland JM, Patel S, Peckham C. The natural history of asthm in childhood. F Epidemiol Community Health 1986;40:121-9.

26 Butler NR, Golding J. From birth to five: a study of the health and behaviour of Britain's five-year-olds. Oxford: Pergamon Press, 1986:158-70

27 Lee DA, Winslow NR, Speight ANP, Hey EN. Prevalence and spectrum of asthma in childhood. Br Med F 1983;286:1256-8.

28 Williams $\mathrm{H}, \mathrm{McNicol} \mathrm{KN}$. Prevalence, natural history and relationship of wheezy bronchitis and asthma in children: an epidemiological study. Br Med f 1969;iv:321-5.

$29 \mathrm{McNicol} \mathrm{KN}$, Williams H. Spectrum of asthma in children. II. Allergic components. Br Med f 1973;iv: 12-6.

30 Platts-Mills TAE, Tovey ER, Mitchell EB, Moszoko H, Nock P, Wilkins SR. Reduction of bronchial hyperreactivity during prolonged allergen avoidance. Lancet 1982;ii:675-8.

(Accepted 5 August 1988) 